\title{
Inventário das árvores urbanas da cidade de Rio Tinto/PB
}

O processo de desenvolvimento urbano tem causado progressivas modificações nas paisagens naturais, com consequente prejuízo para a biodiversidade, causando a destruição, fragmentação e o isolamento de habitats naturais. A arborização urbana proporciona diversos benefícios estéticos, ecológicos e econômicos as populações. O inventário é uma das ferramentas fundamentais para o planejamento e diagnóstico da arborização, e tem como objetivo conhecer o patrimônio arbóreo de uma localidade, fornecendo informações sobre as condições em que se encontram os indivíduos e as prioridades de intervenções. Portanto, o objetivo desse trabalho é realizar o inventário da arborização urbana da cidade de Rio Tinto/PB, para que possa ser utilizado como ferramenta no seu planejamento ambiental. Os dados foram coletados no período de novembro de 2016 a julho de 2018 através do inventário arbóreo. As informações parametrizadas foram: nome popular, espécies, família, origem e eventos fenológicos. Foram percorridos $47 \mathrm{~km}$, compreendendo todas as ruas, avenidas e praças da cidade. Foram catalogados 931 indivíduos, distribuídos em 28 espécies, pertencentes a 12 famílias. A maior parte dos indivíduos é de origem exótica. Conclui-se que atualmente a arborização de Rio Tinto/PB é considerada homogênea. Propõe-se a substituição gradativa dos indivíduos exóticos por nativos que apresentem características ecológicas compatíveis com o meio urbano. Espera-se que esse banco de dados possa ser ponto de partida para o desenvolvimento de novos trabalhos mais pontuais dentro da arborização da cidade de Rio Tinto/PB.

Palavras-chave: Ecologia Urbana; Planejamento Urbano; Arborização Urbana.

\section{Inventory of the urban trees of the city of Rio Tinto/PB}

The process of urban development has caused progressive changes in natural landscapes, with consequent damage to biodiversity, causing the destruction fragmentation and isolation of natural habitats. The urban afforestation provides several aesthetic, ecological and economic benefits to the populations. The inventory is one of the fundamental tools for the planning and diagnosis of afforestation, and aims to know the arboreal heritage of a locality, providing information on the conditions in which the individuals are and the priorities of interventions. Therefore, the objective of this work is to carry out the inventory of the urban arborization of the city of Rio Tinto/PB, so that it can be used as a tool in its environmental planning. The data were collected from November 2016 to July 2018 through the tree inventory. The parameterized information was: popular name, species, family, origin and phenological events. They were covered $47 \mathrm{~km}$, comprising all the streets, avenues and squares of the city. We cataloged 931 individuals, distributed in 28 species, belonging to 12 families. Most individuals are of exotic origin. It is concluded that currently the Rio Tinto/PB afforestation is considered homogeneous. It proposes the gradual replacement of exotic individuals by natives with ecological characteristics compatible with the urban environment. It is hoped that this database may be the starting point for the development of new, more timely works within the forestation of the city of Rio Tinto/PB.

Keywords: Urban Ecology; Urban planning; Urban Arborization.

\section{Topic: Ciências Florestais}

Reviewed anonymously in the process of blind peer.
Received: $10 / 12 / 2018$

Approved: 05/01/2019
Fabrício Ferreira Jerônimo

Universidade Federal da Paraíba, Brasil

http://lattes.cnpq.br/6077178085893245

fabricio.jf102@gmail.com

\section{Sofia Erika Moreira Gomes}

Universidade Federal da Paraíba, Brasi

http://lattes.cnpq.br/8505539177135230

sofiaerika@gmail.com

Zelma Glebya Maciel Quirino

Universidade Federal da Paraíba, Brasi

http://lattes.cnpq.br/2654243440511579

http://orcid.org/0000-0003-0396-107X

zelmaglebya@gmail.com

\section{Referencing this:}

JERÔNIMO, F. F.; GOMES, S. E. M.; QUIRINO, Z. G. M.. Inventário das árvores urbanas da cidade de Rio Tinto/PB. Revista lbero Americana de Ciências Ambientais, v.10, n.1, p.1-9, 2019. DOI: http://doi.org/10.6008/CBPC2179-6858.2019.001.0001 


\section{INTRODUÇÃO}

O processo de desenvolvimento urbano tem causado progressivas modificações nas paisagens naturais, com consequente prejuízo para a biodiversidade, causando a destruição, fragmentação e o isolamento de habitats naturais. As áreas urbanas têm recebido grande atenção para instalação de áreas verdes que venham a amenizar os impactos ambientais e exercer funções de estética e de lazer, além da conservação de espécies.

A arborização urbana associada à manutenção da qualidade ambiental das cidades e ao bem-estar das populações, proporciona diversos benefícios estéticos, ecológicos e econômicos (SANTOS et al., 2012; SILVA et al., 2016), tais como: melhoria da qualidade de ar, diminuição das ilhas de calor, redução com dos custos de refrigeração artificial, valorização econômica de imóveis, redução de barulhos, entre outros (SANTOS et al., 2012; DAMO et al., 2015; QUISSINDO et al., 2016; LIMA NETO et al., 2016).

No entanto a arborização deve ser feita de forma adequada, com o uso de espécies nativas de região para que favoreça a fauna local, a manutenção da flora e a infraestrutura, pois são espécies adaptadas ao clima e as condições biogeográficas. Porém a grande maioria dos trabalhos de arborização prima por espécies de valor estético e de fácil obtenção, as quais nem sempre são espécies nativas. Além da invasão das áreas naturais por espécies exóticas, isso causa diversos tipos de problemas dentro da cidade.

O inventário é uma das ferramentas fundamentais para o planejamento e diagnóstico da arborização, e tem como objetivo conhecer o patrimônio arbóreo de uma localidade, fornecendo informações sobre as condições em que se encontram os indivíduos e as prioridades de intervenções, seja com tratamentos fitossanitários, remoção de árvores e/ou plantios e replantios, bem como, para indicar as necessidades de podas entre outros (SANTOS et al., 2012; LIMA NETO et al., 2012; ASSUNÇÃO et al., 2014; SCHWAB et al., 2014; BRITO et al., 2012). Portanto, o objetivo desse trabalho é realizar o inventário da arborização urbana da cidade de Rio Tinto/PB, para que possa ser utilizado como ferramenta no seu planejamento ambiental, e assim contribuir para a expansão das áreas verdes, remanescentes de Mata Atlântica e mitigar os impactos antrópicos.

\section{MATERIAIS E MÉTODOS}

\section{Caracterização da área de estudo}

O estudo foi realizado na área urbana do município de Rio Tinto, situado na microrregião do Litoral Norte e mesorregião da Zona da Mata, Estado da Paraíba (Figura 1). Está inserido entre as coordenadas $06^{\circ}$ $48^{\prime} 10^{\prime \prime} \mathrm{S}$ e $35^{\circ} 04^{\prime} 51^{\prime \prime} \mathrm{W}$, distando cerca de $53 \mathrm{~km}$ da capital, João Pessoa. Possui uma extensão territorial de 466 km²e população estimada 24.000 habitantes (IBGE, 2018).

O clima desta região é denominado de Am (tropical e chuvoso) com temperaturas médias que oscilam entre $24^{\circ} \mathrm{C}$ a $27^{\circ} \mathrm{C}$ e variações pluviométricas entre 1800 a $2000 \mathrm{~mm} /$ ano, segundo a classificação de Koppen, atualizada por Alvares et al. (2013). Apresenta sazonalidade bem definida, com verão entre os meses de novembro a abril, e período chuvoso de maio a outubro. 
Alguns fatores foram levados em consideração para a escolha da área de estudo. Um deles é o fato da área urbana de Rio Tinto/PB estar inserida dentro de uma Área de Proteção Ambiental (APA da Barra do Rio Mamanguape) e próxima à Reserva Biológica Guaribas (REBIO - SEMA III) (Figura 1). Outro fator importante é não haver registros de planos de arborização da cidade.

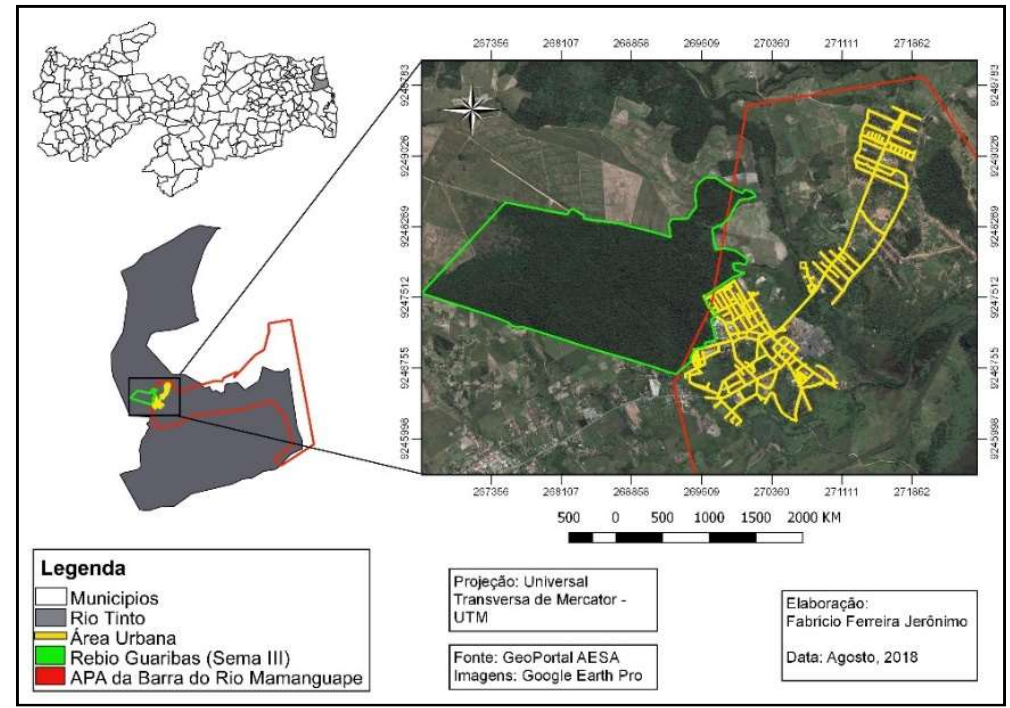

Figura 1: Mapa de localização da área estudada no município de Rio Tinto/PB.

\section{Coleta de Dados}

Os dados foram coletados através do inventário arbóreo quali-quantitativo de acordo com (BORTOLETO et al., 2007; COLETTO et al., 2008; MIRANDA et al., 2015; SILVA et al., 2016) no qual foi feito o levantamento de todos os indivíduos arbóreos presentes na cidade. A coleta de dados foi realizada no período de novembro de 2016 a julho de 2018. As características e as variáveis analisadas em campo foram efetuadas com o auxílio de uma planilha de levantamento de dados de acordo com Silva Filho et al. (2002) e Lacerda et al. (2011), adaptada para as condições locais.

As informações foram parametrizadas da seguinte forma: Características das espécies: Nome vulgar: O nome popular (local) atribuído à árvore; Espécie, família e origem: A nomenclatura científica seguiu as normas propostas pelo APG III, Lorenzi (2002) e a origem das espécies foi verificada utilizando o banco de dados da lista de espécies da Flora do Brasil e Lorenzi et al. (2018); Eventos fenológicos: Observou-se as fenofases dos indivíduos no momento de coleta, como: presença de folhas, flores e frutos, e através da literatura identificou-se as possíveis síndromes de dispersão.

\section{RESULTADOS E DISCUSSÃO}

\section{Características das Espécies e Frequência}

No inventário da arborização da cidade de Rio Tinto - PB foram percorridos 47 km, compreendendo todas as ruas, avenidas e praças. Com isto foram catalogados um total de 931 indivíduos arbóreos (Figura 2), distribuídos em 28 espécies, pertencentes a 12 famílias botânicas (Tabela 1). As famílias que apresentaram maior riqueza foram Fabaceae, com 11 espécies e Myrtaceae, com 3 espécies. 
Tabela 1: Famílias botânicas, nome popular, número de indivíduos ( $\mathrm{NI}$ ), frequência relativa (Fr\%), síndromes de dispersão e origem das espécies arbóreas inventariadas na arborização da cidade de Rio Tinto/PB.

\begin{tabular}{|c|c|c|c|c|c|}
\hline \multicolumn{6}{|l|}{ FAMÍLIA } \\
\hline Nome científico & Nome Popular & $\mathbf{N}^{\circ}$ de Indiv. & Freq. \% & Síndrome de dispersão & Origem \\
\hline \multicolumn{6}{|l|}{ ANACARDIACEAE } \\
\hline Mangifera indica $\mathrm{L}$. & mangueira & 8 & 0,86 & Zoocórica & Exótica \\
\hline Anacardium occidentale L. & cajueiro & 1 & 0,10 & Zoocórica & Nativa \\
\hline \multicolumn{6}{|l|}{ ARAUCARIACEAE } \\
\hline Araucaria heterophylla (Salisb.) Franco & pinheiro-de-norfolk & 1 & 0,10 & Autocórica & Exótica \\
\hline \multicolumn{6}{|l|}{ BIGNONIACEAE } \\
\hline Tabebuia alba (Chamiso) Sandwith & ipê amarelo & 1 & 0,10 & Anemocórica & Nativa \\
\hline Tabebuia pentaphylla (Vell.) & ipê roxo & 1 & 0,10 & Anemocórica & Nativa \\
\hline \multicolumn{6}{|l|}{ CASUARINACEAE } \\
\hline Casuarina equisetifolia J. R. \& G. Forst. & casuarina-da-praia & 4 & 0,43 & Autocórica & Exótica \\
\hline \multicolumn{6}{|l|}{ COMBRETACEAE } \\
\hline Terminalia catappa L. & castanhola & 194 & 20,88 & Zoocórica & Exótica \\
\hline \multicolumn{6}{|l|}{ CUPRESSACEAE } \\
\hline Juniperus chinensis L.Variegata & cipreste-variegado & 2 & 0,21 & Autocórica & Exótica \\
\hline \multicolumn{6}{|l|}{ FABACEAE } \\
\hline Tamarindus indica $\mathrm{L}$. & tamarindo & 2 & 0,21 & Zoocórica & Exótica \\
\hline Clitoria fairchildiana R. A. Howard. & sombreiro & 11 & 1,18 & Autocórica & Exótica \\
\hline Peltophorum dubium (Spreng.) Taub. & faveira & 1 & 0,10 & Autocórica & Nativa \\
\hline Delonix regia (Bojer ex Hook.) Raffin & flamboyant & 6 & 0,64 & Autocórica & Exótica \\
\hline Erythrina indica Lam. Var. picta hort. & brasileirinho & 1 & 0,10 & Autocórica & Exótica \\
\hline Adenanthera pavonina $\mathrm{L}$. & olho de pombo & 120 & 12,91 & Autocórica & Exótica \\
\hline Caesalpinia echinata Lam. & pau-brasil & 12 & 1,29 & Autocórica & Nativa \\
\hline Prosopis juliflora (Sw.) DC. & algaroba & 6 & 0,64 & Zoocórica & Exótica \\
\hline Pithecellobium dulce (Roxb.) Benth. & mata fome & 33 & 3,55 & Autocórica & Exótica \\
\hline Cassia fistula $\mathrm{L}$. & chuva-de-ouro & 1 & 0,10 & Autocórica & Exótica \\
\hline Senna siamea (Lam.) H. S. Irwin \& Barneby & canafístula & 161 & 17,33 & Autocórica & Exótica \\
\hline \multicolumn{6}{|l|}{ MALVACEAE } \\
\hline Hibiscus tiliaceus L. & algodão-de- praia & 101 & 10,87 & Autocórica & Exótica \\
\hline Guazuma ulmifolia Lam. & mutambo & 1 & 0,10 & Zoocórica & Nativa \\
\hline \multicolumn{6}{|l|}{ MELIACEAE } \\
\hline Azadirachta indica A. Juss & nim indiano & 32 & 3,44 & Zoocórica & Exótica \\
\hline \multicolumn{6}{|l|}{ MYRTACEAE } \\
\hline Syzygium malaccense (L.) Merr. \& L.M. Perry & jambo-vermelho & 6 & 0,64 & Zoocórica & Exótica \\
\hline Eugenia uniflora L. & pitanga & 1 & 0,10 & Zoocórica & Exótica \\
\hline Psidium guajava $\mathrm{L}$. & goiabeira & 1 & 0,10 & Zoocórica & Exótica \\
\hline \multicolumn{6}{|l|}{ MORACEAE } \\
\hline Ficcus benjamina $\mathrm{L}$. & figueira & 195 & 20,99 & Zoocórica & Exótica \\
\hline Ficus microcarpa L. f. & figueirinha & 22 & 2,36 & Zoocórica & Exótica \\
\hline \multicolumn{6}{|l|}{ URTICACEAE } \\
\hline Cecropia palmata Willd & embaúba & 5 & 0,53 & Zoocórica & Nativa \\
\hline Indeterminada & Não identificada & 1 & 0,10 & - & - \\
\hline
\end{tabular}

Com relação ao número de indivíduos por família, 867 (93,12\%) do total pertencem apenas a quatro famílias, sendo Fabaceae $(38,02 \%)$ a de maior número, seguida de Moraceae (23,30\%), Combretaceae (20,83\%) e Malvaceae (10,97\%). A família Fabaceae foi a que apresentou maior dominância de gênero, apresentando ampla superioridade com relação às outras famílias. Souza e Lorenzi (2009) falam que esta possui uma distribuição cosmopolita, com aproximadamente 18 mil espécies, representando um dos maiores grupos das Angiospermas. Os mesmos autores ainda falam que essa família é a mais utilizada na arborização urbana das cidades brasileiras, uma vez que diversas espécies desse grupo são empregadas como ornamentais.

Neste trabalho observou-se poucas espécies representadas por muitos indivíduos, dentre elas destacam-se F. benjamina com 195 indivíduos (20,94\%), T. catappa com 194 (20,83\%), S. siamea com 161 
(17,29\%) e A. pavonina com 120 (12,88\%), juntas perfazendo um total de 669 indivíduos inventariados (71,85\%). Isso indica que não há planejamento em relação à escolha de indivíduos arbóreos na cidade, e que provavelmente o plantio de espécies tenha sido efetuado de forma aleatória, sendo até mesmo realizada pela população. Estas espécies são comuns na arborização de várias cidades brasileiras (LORENZI et al., 2018), a sua dominância indica a alta capacidade adaptativa em meio urbano e a condições desfavoráveis como: solos compactados, poluição e baixa quantidade de água, dentre outros, indicando alta rusticidade e plasticidade fenotípica.

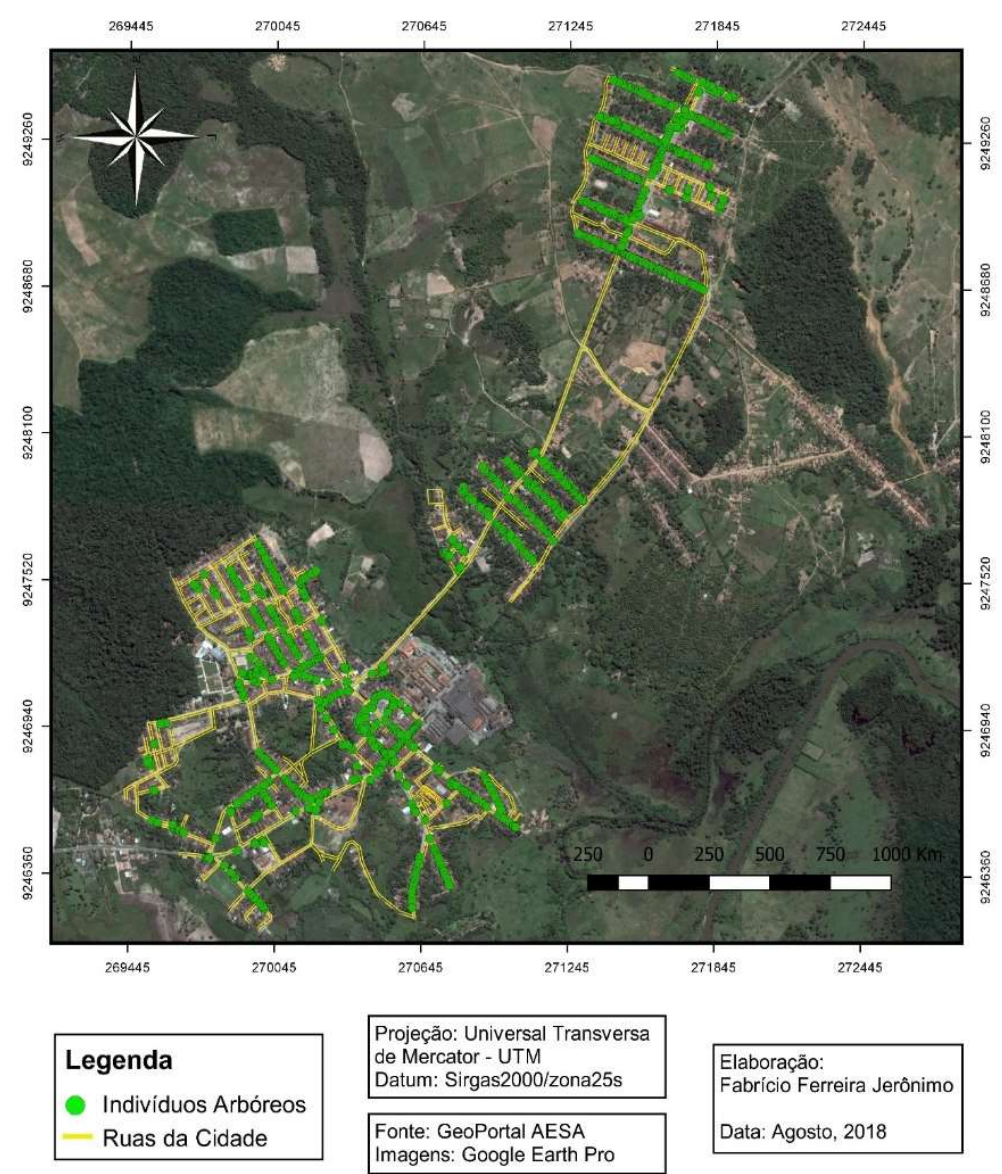

Figura 2: Distribuição espacial dos indivíduos arbóreos catalogados na arborização urbana de Rio Tinto/PB.

Em relação à utilização das espécies mais frequentes na área de estudo, o uso de $F$. benjamina, muito comum nas ruas e calçadas da cidade indica influência de um modismo ocorrido em todo Brasil, por apresentar grande valor ornamental de suas folhas e pela forma geral da planta (BARROS et al., 2010; SANTOS JÚNIOR et al., 2014). De acordo com Lima Neto et al. (2011), Albertin et al. (2011), Santos Júnior et al. (2014) e Lorenzi et al. (2018) trata-se de uma árvore inconveniente para arborização de ruas e avenidas, pelo excessivo vigor do sistema radicular, podendo danificar as construções, como calçadas e canteiros no local em que está inserida. Uma das características dessa espécie sobressair em ambientes urbanos é ser tolerante a podas e ser utilizada em vasos quando jovens e posteriormente nas ruas (LORENZI et al., 2018).

A espécie T. catappa é uma árvore de copa densa e ampla, que proporciona bom sombreamento no local onde está inserida (LORENZI et al., 2018). Contudo, observou-se no período de coleta, que essa espécie 
produz grande quantidade de biomassa pela queda de folhas, ocasionando entupimento de calhas e redes de esgotos, deixando o local mais sujo, demandando maior ocupação dos responsáveis pela limpeza da cidade. Além disso, ela possui raízes vigorosas, que acarreta conflitos com as infraestruturas urbanas, sendo uma espécie não indicada para arborização (MIRANDA et al., 2015). Segundo Cielo Filho et al. (2002), essa espécie é dispersa por aves e morcegos e pode se estabelecer em outras áreas, como por exemplo, remanescentes florestais.

As espécies S. siamea e A. pavonina são árvores com características ornamentais frequentemente cultivadas em praças e jardins, sendo também utilizadas na arborização de ruas nas regiões nordeste e sudeste do Brasil (LORENZI et al., 2018). Algumas características dessas espécies são rápido crescimento, grande rusticidade e tolerância a podas de contenção, o que favorece a sua utilização na arborização urbana. De acordo com Rocha et al. (2004), elas não são indicadas para uso dentro das cidades, por possuir madeira de baixa resistência mecânica, que quebra com facilidade, podendo ocasionar riscos e prejuízos à população.

Com relação à origem dos indivíduos inventariados, constatou-se que $97,63 \%$ são exóticos e 2,37\% são nativos. Souza et al. (2015) relatam que a utilização de espécies exóticas predomina nas ruas, avenidas e praças brasileiras, totalizando aproximadamente $80 \%$ dos exemplares, e devido a frequente utilização dessas espécies, muitas vezes são consideradas nativas pela comunidade em geral, ocasionando plantios cada vez mais intensos nas áreas urbanas.

Pode-se observar que a prática de utilização de espécies exóticas não é apenas um problema em Rio Tinto/PB, mais também de outras cidades. Resultados semelhantes foram observados em trabalhos que realizaram o censo da arborização, como por exemplo Miranda et al. (2015) no município de Godoy Moreira/PR, onde constataram que 76\% das espécies arbóreas eram exóticas ou exóticas invasoras, e Lima Neto et al. (2016) na cidade de Boa Vista/RR, onde 53,2\% das espécies são exóticas e 46,8\% são nativas.

Em termos ecológicos, é tecnicamente recomendável a utilização de espécies nativas da região de estudo, principalmente para garantir as relações ecológicas co-evolutivas e genéticas envolvendo fauna e flora dentro do ambiente urbano (PAIVA et al., 2010).

A preocupação relacionada ao cultivo de espécies exóticas em Rio Tinto/PB ocorre principalmente pelo fato desta cidade estar inserida em uma Unidade de Conservação (SEMA III) (Figura 1), um dos poucos remanescentes de Floresta Atlântica da região Nordeste preservados em Unidades de Conservação (FEIJÓ et al., 2016). A presença de espécies exóticas próxima a este ambiente pode ocasionar a sua propagação por dispersão natural.

No Brasil, a falta de manejo de espécies exóticas em áreas protegidas é, sem dúvida, o fator de maior preocupação em relação ao avanço das invasões biológicas (ZILLER et al., 2013). De acordo com esses autores, algumas espécies devem ser observadas por possuírem alta capacidade de dispersão e estabelecimento, e serem consideradas invasoras. Por exemplo, $P$. juliflora é caracterizada como espécie invasora que domina os ambientes colonizados e reduz drasticamente a participação das espécies nativas (PEGADO et al., 2006; ANDRADE et al., 2009). Portanto, a utilização dessa espécie deve ser feita com bastante cautela ou mesmo evitada na área de estudo. 
Diferentemente das espécies exóticas, uma escolha técnica e direcionada ao cultivo de espécies nativas é essencial, pois oferece às áreas urbanas árvores mais resistentes a pragas e serve, não apenas como fator de permanecia da flora local, como também um facilitador para preservação da fauna e o seu deslocamento entre a cidade e remanescentes florestais, visto que as árvores proporcionariam abrigo, alimento e vias de condução mais seguras no ambiente urbano (LIMA NETO et al., 2016).

Portanto, deve-se investir em estudos sobre as espécies nativas e seus potenciais, para tentar aumentar a diversidade das mesmas no meio urbano. Paiva et al. (2010) destacam a importância de estudar indivíduos nativos com características positivas, não somente relacionadas a parâmetros estéticos, mas também funcionais e ecológicos, que possibilitem seu cultivo no meio urbano, permitindo um melhor aproveitamento de seus serviços ambientais.

\section{Eventos Fenológicos}

Durante o período de coleta, observou-se que 923 indivíduos estavam somente com folhas, 257 com flores, 279 estavam com frutos, 172 estavam com flores e frutos. As alterações fenológicas nas árvores são provocadas pelas mudanças estacionais, que segundo Gonçalves et al. (2015), correspondem à diversidade de cores e texturas, seja cores das florações ou a textura e coloração das folhas e galhos, que, ao longo do ano, vão proporcionando visuais diferentes em uma mesma paisagem. Santos et al. (2015) falam que o registro de floração e frutificação das espécies que compõem a arborização urbana é importante para definir a época de poda mais adequada para cada espécie, e que as podas devem ser evitadas nesses períodos em que as espécies destinam a sua energia para a fase de reprodução.

Com relação ao tipo de dispersão das espécies catalogadas, constatou-se a predominância da zoocoria $(48,14 \%)$, seguida de autocoria $(48,14 \%)$ e anemocoria $(7,40 \%)$ (Tabela 1$)$. Esses dados foram compilados a partir de observações dos caracteres dos frutos, os quais foram descritos de acordo com informações da literatura. A dispersão de frutos das espécies inventariadas não é uma característica estudada na maioria dos trabalhos de arborização urbana. Porém é importante, pois indica quais os tipos de animais que podem estar sendo atraídos para as áreas urbanas e possivelmente dispersar as sementes (JERONIMO et al., 2017). Essa característica é importante no planejamento da arborização, não somente do ponto de vista ecológico, mais também está relacionada aos interesses paisagísticos que focam no plantio de árvores para atração de determinadas espécies animais.

\section{CONCLUSÕES}

Conclui-se que atualmente a arborização de Rio Tinto/PB é considerada homogênea, havendo muitos indivíduos da mesma espécie. A grande frequência de espécies exóticas diagnosticada deve ser evitada, principalmente quanto às potencialmente invasoras. Propõe-se a substituição gradativa dos indivíduos exóticos por nativos que apresentem características ecológicas compatíveis com meio urbano. São sugestões viáveis a realização de novos plantios, substituições e manutenções que levem em conta as condições adequadas para que a vegetação seja saudável. As ações recomendadas para um melhor aproveitamento 
dos serviços proporcionados pelas árvores urbanas precisam ser decididas com base em um planejamento prévio. Espera-se que o presente banco de dados possa ser ponto de partida para o desenvolvimento de novos trabalhos paisagísticos na cidade de Rio Tinto/PB.

\section{REFERÊNCIAS}

ALBERTIN, R. M.; ANGELIS, R.; NETO, G. A.; ANGELIS, B. L. D.. Diagnóstico quali-quantitativo da arborização viária de Nova Esperança, Paraná, Brasil. Revista da Sociedade Brasileira de Arborização Urbana, Piracicaba , v.6, n.3, p.128-148, 2011.

ALVARES, C. A.; STAPE, J. L.; SENTALHAS, P. C.; MORAES, G.; LEONARDO, J.; SPAROVEK, G..Köppen'climate classification map for Brazil. Meteorologische Zeitschrift. v.22, n.6, p.711728, 2013. DOI: http://doi.org/10.1127/09412948/2013/0507

ANDRADE, L. A.; FABRICANTE, J. R.; OLIVEIRA, F. X.. Invasão biológica por Prosopis juliflora (Sw.) DC.: impactos sobre a diversidade e a estrutura do componente arbustivo-arbóreo da caatinga no estado do Rio Grande do Norte, Brasil. Acta Bot. Bras., v.23, n.4, p.935-943. 2009.

ASSUNÇÃO, K. C.; LUZ, P. B.; NEVES, L. G.; SOBRINHO, S. P. Levantamento quantitativo da arborização de praças da cidade de Cáceres/MT. Revista da Sociedade Brasileira de Arborização Urbana, Piracicaba, v.9, n.1, p.123-132, 2014.

BARROS, E. F. S.; GUILHERME, F. A. G.; CARVALHO, R. S.. Arborização urbana em quadras de diferentes padrões construtivos na cidade de Jataí. Revista Árvore, Viçosa, v.34, n.2, p.287-295, 2010

BORTOLETO, S.; SILVA FILHO, D. F.; SOUZA, V. C.; FERREIRA, M. A. P. F.; POLIZEL, J. L.; RIBEIRO, R. C. S.. Composição e distribuição da arborização viária da Estância de Águas de São Pedro/SP. Revista da Sociedade Brasileira de Arborização Urbana, v.2, n.3, 2007.

BRITO, C. R.; CASTRO, J. P. M.; BARROS, K. O.; FARIA, A. L. L.. O uso de SIG no inventário de árvores no Campus do Instituto Politécnico de Bragança, Portugal. Geografia Ensino \& Pesquisa, v.16, n.3, 2012.

CIELO FILHO, R.; SANTIN, D. A.. Estudo florístico e fitossociológico de um fragmento florestal urbano - Bosque dos Alemães, Campinas, SP. Revista Brasileira de Botânica, v.25, n.3, p.291-301, 2002.

COLETTO, E. P.; MULLER, N. G.; WOLSKI, S. S.. Diagnóstico da Arborização das vias públicas do município de Sete de Setembro/RS. Revista da Sociedade Brasileira de Arborização Urbana, Piracicaba, v.3, n.2 p.110-122, 2008.

DAMO, A.; HEFLER, S. M.; JACOBI, U. S.. Diagnóstico da arborização em vias públicas dos bairros Cidade Nova e Centro na cidade de Rio Grande - RS. Revista da Sociedade Brasileira de Arborização Urbana, Piracicaba , v.10, n.1, p. 43-60, 2015.

FEIJÓ, A.; NUNES, H.; LANGGUTH, A.. Mamíferos da Reserva Biológica Guaribas, Paraíba, Brasil. Revista Nordestina de Biologia, v.2, p.57-74, 2016.
GONÇALVES, A.; MENEGUETTI, K.. Projeto de arborização como patrimônio da cidade. Ambiente Construído, Porto Alegre, v.15, n.1, p.99-118, 2015.

IBGE. Instituto Brasileiro de Geografia e Estatística. Rio Tinto/PB, 2018.

JERONIMO, F. F.; SILVA, M. A. C.; GOMES, S. E. M.; QUIRINO Z. G. M.. Arborização da Cidade de Pedra Branca/PB: Dados Preliminares. Educação ambiental: Ecopedagogia e Sustentabilidade dos Recursos Naturais. 2017.

LACERDA, R. M. A.; LIRA FILHO, J. A.; SANTOS, R. V. Indicação de espécies de porte arbóreo para a arborização urbana no semiárido paraibano. Revista da Sociedade Brasileira de Arborização Urbana, Piracicaba, v.6, n.1, p.5168, 2011.

LIMA NETO, E. M.; SOUZA, R. M.. Comportamento e características das espécies arbóreas nas áreas verdes públicas de Aracaju, Sergipe. Scientia Plena, Aracaju, v.7, p.1-10, 2011.

LIMA NETO, E. M.; BIONDI, D.; LEAL, L.; SILVA, F. L. R.; FLÁVIA PINHEIRO, A. P.. Análise da Composição Florística de Boa Vista-RR: subsídio para a gestão da Arborização de Ruas Revista da Sociedade Brasileira de Arborização Urbana, Piracicaba, v.11, n.1, p.58-72, 2016.

LIMA NETO, E. M.; BIONDI, D.. Detecção de árvores de ruas da cidade de Curitiba/PR, utilizando fotografias aéreas. Revista Brasileira de Ciências Agrarias, Recife. v.7, n.4, p.641-647, 2012.

LORENZI, H.. Árvores Brasileiras. São Paulo: Nova Odessa 2002.

LORENZI, H.; BACHER, L. B.; TORRES, M. A. V.. Arvores e arvoretas exóticas no Brasil. Nova Odessa: Instituto Plantarum de Estudos da Flora, 2018.

MIRANDA, Y. C.; MACHADO, M. S.; SILVA, L. S.; ESTEVAM, R.; MARTINS NETO, F. F.; CAXAMBU, M. G.. Análise qualiquantitativa da Arborização de ruas do município de Godoy Moreira PR. Revista da Sociedade Brasileira de Arborização Urbana, Piracicaba, v.10, n.1, p.71-81, 2015.

PAIVA, A. V.; LIMA, A. B. M.; CARVALHO, A.; JUNIOR, A. M.; GOMES, A.; MELO, C. S.; FARIAS, C. O.; REIS, C.; BEZERRA, C; JUNIOR, E. A. S.; MACEDO, E.; LIMA, E. S.; SOBRINHO, F.; SILVA, F. M.; BONFIM, J. C.; JUNIOR, L. S.; CORREA, M.; DUMONT, M. L.; JUNIOR, M. A. I.; PANTOJA, N. V.; DAVILA, R. M.; GABRIEL, R.; SILVA, R. A.; CUNHA, R. M.; OLIVEIRA, R. S. DIAS, R.; NICHELI, S. P.; COSTA, S. SOUZA, T. C.; PEREIRA, T. F.; CASTELO, Z.; FERRARI, Z. S.. Inventario e diagnostico da arborização urbana viária de Rio Branco/AC. Revista da Sociedade Brasileira de Arborização Urbana, Piracicaba, v.5, n.1, p.144-159, 2010. 
PEGADO, C. M. A.; ANDRADE, L. A.; FELIX, L. P.; PEREIRA, I. M.. Estudos da invasão biológica de algaroba - Prosopis juliflora (SW.) DC. Sobre a composição e a estrutura do estrato arbustivo-arbóreo da caatinga no Município de Monteiro, PB, Brasil. Acta Bot. Bras., v.20, n.4, p.887-898. 2006.

QUISSINDO, I. A. B.; OCONOR, E. F.; LUNA, D. P.. Avaliação da vegetação arbórea nas principais ruas da cidade do HuamboAngola Revista da Sociedade Brasileira de Arborização Urbana, Piracicaba, v.11, n.1, p.43-57, 2016.

ROCHA, R. T.; LELES, P. S. S.; OLIVEIRA NETO, S. N.. Arborização de vias públicas em nova Iguaçu, RJ: o caso dos bairros Rancho Novo e Centro. Revista Árvore, Viçosa, v.28, n.4, p.599-607, 2004.

SANTOS, C. Z. A.; FERREIRA, R. A.; SANTOS, L. R.; SANTOS, L. I.; GOMES, S. H.; GRAÇA, D. A. S.. Análise qualitativa da arborização urbana de 25 vias públicas da cidade de Aracaju/SE. Ciência Florestal, Santa Maria, v.25, n.3, p.751763, 2015.

SANTOS, T. O. B.; LISBOA, C. M. C. A.; CARVALHO, F. G. Análise da arborização viária do bairro de Petrópolis, Natal/RN: Uma Abordagem para diagnóstico e planejamento da flora urbana, Revista da Sociedade Brasileira de Arborização Urbana, Piracicaba, v.7, n.4, p.90-106, 2012.

SANTOS JUNIOR, A.; COSTA, L. M.. Espécies empregadas na arborização urbana do bairro Santiago, JI-Paraná/RO. Revista da Sociedade Brasileira de Arborização Urbana, Piracicaba, v.9, n.1, p.78-91, 2014.
SILVA FILHO, D. F.; PIZETTA, P. U. C.; ALMEIDA, J. B. S. A.; PIVETTA, K. F. L.; FERRAUDO, A. S.. Banco de dados relacional para cadastro, avaliação e manejo da arborização em vias públicas. Revista Árvore, Viçosa, v.26, n.5, p.629642, 2002.

SILVA, K. A. R.; LELES, P. S. S.; GIÁCOMO, R. G.; MENDONÇA B. A. F.. Diagnóstico e uso de Geoprocessamento para manejo da Arborização Urbana do Bairro Centro da Cidade do Rio de Janeiro/RJ. Revista da Sociedade Brasileira de Arborização Urbana, Piracicaba, v.11, n.4, p.98-114, 2016.

SOUZA, P. F.; BOURSCHEID, C. D.; POMPÉO, P. N.; STANG, M. B.; MANFROI, J.; RODRIGUES, M. D. S.; SILVA, A. C.; HIGUCHI, P.. inventário e recomendações para a arborização do centro da cidade de São Joaquim/SC. Revista da Sociedade Brasileira de Arborização Urbana, v.9, n.4, p.99-112, 2015.

SOUZA, V. C.; LORENZI, H.. Botânica Sistemática: Guia ilustrado para identificação das famílias deFanerógamas nativas e exóticas no Brasil, baseado em APG II. 2 ed. Nova Odessa: Instituto Plantarum, 2009.

SCHWAB, N. T.; GIRARDI, L. B.; NEUHAUS, M.; BACKES, F. A. A. L.; BELLÉ, R. A.; MENEGAES, J. F.. Diversidade florística do bairro Nossa Senhora das Dores em Santa Maria/RS. Revista Brasileira de Horticultura Ornamental, Campinas, v. 20, n. 2, p.155-162, 2014.

ZILLER, S. R.; DECHOUM, M. S.. Plantas e Vertebrados Exóticos Invasores em Unidades de Conservação no Brasil. Biodiversidade Brasileira, v.3, n.2, p.4-31, 2013. 